\title{
Intrinsic PEEP and cardiopulmonary interaction in patients with COPD and acute ventilatory failure
}

\author{
V.M. Ranieri, M. Dambrosio, N. Brienza
}

Intrinsic PEEP and cardiopulmonary interaction in patients with COPD and acute ventilatory failure. V.M. Ranieri, M. Dambrosio, N. Brienza. (CERS Journals Ltd 1996.

ABSTRACT: Deviation of end-expiratory lung volume from the elastic equilibrium volume of the respiratory system is recognized as a cardinal feature in mechanically-ventilated patients with severe chronic obstructive pulmonary disease (COPD) and acute ventilatory failure (AVF). The presence of dynamic hyperinflation implies that alveolar pressure remains positive throughout expiration. At the end of the expiration, this positive pressure is named intrinsic positive end-expiratory pressure $(\mathbf{P E E P} \mathbf{i})$.

Recent studies have suggested that, in COPD patients with expiratory flow limitation, the application of external PEEP during assisted mechanical ventilation, or the use of continuous positive airway pressure (CPAP) in spontaneously breathing patients, can counterbalance and reduce the inspiratory threshold load imposed by PEEPi, without causing further increase in lung volume and alveolar and intrathoracic pressures until a critical value of PEEP ( $P$ crit) is reached. Above this critical limit further hyperinflation is observed.

A specific and characteristic role of PEEPi in compromising the heart function in COPD patients during AVF may be identified based on: 1) an increase in right ventricular impedance due to lung hyperinflation; 2) an increase in the venous return to the right ventricle and, consequently, a leftward shift of the septum caused by the large negative deflections in intrathoracic pressure due to the inspiratory threshold load; 3) a further increase in venous return to the right ventricle, with the eventual collapse of the vena cava caused by the expiratory recruitment of abdominal muscles; and 4) hypoxia and hypercapnia consequent to acute ventilatory failure, which may further increase right ventricular impedance and venous return to the right ventricle.

All these phenomenon are directly correlated to the large negative intrathoracic pressure developed by the respiratory muscles to overcome the inspiratory threshold caused by intrinsic positive end-expiratory pressure (preload effect), and to the increase in lung volume (afterload effect). Application of positive end-expiratory pressure/continuous positive airway pressure in chronic obstructive pulmonary disease patients during acute ventilatory failure may, hence, unload the respiratory muscles as well as the heart.

Eur Respir J., 1996, 9, 1283-1292.
Istituto di Anestesiologia e Rianimazione, Università di Bari, Ospedale Policlinico, Bari, Italy.

Correspondence: V.M. Ranieri

Istituto di Anestesiologia e Rianimazione Università di Bari

Ospedale Policlinico

Piazza Giulio Casare 70100

Bari

Italy

Keywords: Acute ventilatory failure cardiopulmonary interaction chronic obstructive pulmonary disease continuous positive airway pressure intrinsic positive end-expiratory pressure

Received: July 121995

Accepted after revision January 301996

Supported by Consiglio Nazionale delle Recerche (grant 94.02325.CT04).
Deviation of end-expiratory lung volume (EELV) from the elastic equilibrium volume (or relaxation volume $\left(V_{\mathrm{r}}\right)$ ) of the respiratory system is recognized as a cardinal feature in patients with acute ventilatory failure (AVF) [1]. The presence of dynamic hyperinflation implies that alveolar pressure remains positive throughout expiration. At the end of the expiration, this positive pressure is termed auto positive end-expiratory pressure (auto PEEP) or intrinsic positive end-expiratory pressure (PEEPi) $[2,3]$. PEEPi and dynamic hyperinflation have been described in mechanically-ventilated chronic obstructive pulmonary disease (COPD) patients, in whom expiratory flow limitation had occurred as a consequence of dynamic airway compression [1-8]. Recent studies have suggested that, in COPD patients with expiratory flow limitation, the application of external PEEP during assisted mechanical ventilation [9], or the use of continuous positive airway pressure
(CPAP) in spontaneously breathing patients [10], can counterbalance and reduce the inspiratory threshold load imposed by PEEPi, without causing further hyperinflation. Under these circumstances, CPAP/PEEP counterbalances PEEPi, thus reducing the inspiratory effort required either to trigger the ventilator or to resume spontaneous breathing. Therefore, in contrast to traditional opinion, recent clinical studies support the use of PEEP in mechanically-ventilated COPD patients. Furthermore, it has been suggested that application of PEEP may facilitate weaning from mechanical ventilation in such patients by reducing the work of breathing and dyspnoea without causing further hyperinflation $[10,11]$.

The physiological background supporting the use of CPAP/PEEP to counterbalance PEEPi and unload the respiratory muscles has been examined by GOTTFRIED [11]. More recently, Rossi and co-workers [12] have elegantly 
reviewed the complex physiological mechanisms leading to PEEPi. Therefore, before proceeding with a discussion of the implication of PEEPi on the cardiopulmonary interaction during weaning from mechanical ventilation, we will simply stress the conclusions of GOTTFRIED [11] and Rossi and co-workers [12]. Application of PEEP in COPD patients with PEEPi due to a documented flow limitation mechanism does not cause an increase in lung volume, alveolar and intrathoracic pressure until a critical value of PEEP ( $P$ crit) is reached. Above this critical limit, further hyperinflation is observed. Conversely, if PEEPi is not due to expiratory flow limitation but to high minute ventilation, increased expiratory resistance, and expiratory recruitment of abdominal muscles, application of PEEP will cause further hyperinflation, worsening respiratory mechanics, muscle activity, and haemodynamics (table 1).

The aim of this article will be: 1) to review the consequences of PEEPi on the cardiopulmonary interaction during the weaning process; and 2) to examine the effects of CPAP on the cardiopulmonary interaction in COPD patients during weaning from mechanical ventilation.

\section{Effects of PEEPi on cardiopulmonary interaction during weaning}

Although mean pulmonary artery pressure $\left(\bar{P}_{\mathrm{pa}}\right)$ is $25-35 \mathrm{mmHg}$ in most patients with stable COPD [13, $14]$, during exercise $[15,16]$ and exacerbation of COPD [17-23], $P$ pa may rise to $45-70 \mathrm{mmHg}$. Although the cause of the increased afterload in COPD patients has not been clearly established, hypoxaemia appears to be a major factor leading to pulmonary hypertension due to its powerful pulmonary vasoconstrictor effect [24, 25]. In addition, changes in pulmonary mechanics play an important role [24-27] in the genesis of pulmonary hypertension.

Matthay et al. [15] measured right (RVEF) and left (LVEF) ventricular ejection fraction at rest and during exercise in patients with COPD. RVEF was abnormal at rest in only eight out of 30 patients with COPD. However, 23 patients had an abnormal right ventricular (RV) response to submaximal exercise. Airway obstruction and arterial hypoxaemia were significantly more severe in patients with abnormal right ventricular (LV) exercise reserve than in patients with normal reserve. Left ventricular performance was abnormal at rest in only four patients and during exercise in only six patients. A restricted, relatively nonrecruitable pulmonary vascular bed with high $\bar{P}$ pa was considered to be the most likely mechanism for the failure of RVEF to increase normally with exercise [15]. To ascertain whether the increase in $\bar{P}$ pa might be related to changes in intrathoracic pressure during exercise, MAHLER et al. [16] placed an oesophageal balloon in each patient to correct for intrathoracic pressure. After correction for intrathoracic pressure, they still found elevated values of $\bar{P}$ pa and pulmonary vascular resistance (PVR). This acute elevation both in $\bar{P}$ pa and PVR led to an adaptive rise in preload, as measured by an increase in right ventricular end-diastolic volume (RVEDV) [16].

To gain a better understanding of the causes of right ventricular dysfunction in COPD patients during AVF, DHAINAut et al. [20] performed a study in 10 spontaneously breathing COPD patients, using a pulmonary artery catheter with a fast response thermistor and measuring oesophageal pressure. Two-dimensional echocardiography allowed simultaneous assessment of changes in the dimensions of the right ventricle and inferior vena cava (IVC). At end-expiration, the minimal RVEF was associated with a reduction of the right ventricular enddiastolic diameter and enlargement of the dimensions of the IVC. During inspiration, right ventricular end-diastolic diameter increased and IVC collapsed, suggesting that the decrease in intrathoracic pressure increased venous return and right ventricular preload [20]. However, despite this enhanced venous return to the right ventricle during inspiration, RVEF, intracavitary right ventricular pressure, and pulmonary artery pulse pressure did not increase [20] (fig. 1).

Settle et al. [30], studying stable COPD patients, observed an increase in RV dimension during inspiration associated with a reduction in LV dimensions. Similarly, JARDIN and co-workers [31], studying mild acute exacerbation of COPD, found increased RV dimensions when compared to a control group. The enlargement was associated with septal flattening and decreased LV dimensions. LemAire et al. [17] studied the haemodynamic effects of rapid weaning from mechanical ventilation in 15 patients with exacerbation of severe COPD and pre-existing heart disease. The major finding of the latter study was that transmural LV filling pressure markedly increased when weaning from mechanical ventilation was attempted in COPD patients. After $10 \mathrm{~min}$ of spontaneous ventilation, the mean transmural pulmonary artery occlusion pressure (PAOP) increased from $7.5 \pm 5$

Table 1. - Physiological mechanisms accounting for intrinsic positive end-expiratory pressure $(\mathrm{PEEP} \mathrm{i})$ and relative consequences of application of PEEP levels lower than PEEPi

$\begin{array}{ll}\text { PEEPi and dynamic } & \text { Applied PEEP }<\text { PEEPi } \\ \text { hyperinflation due to } \\ \text { expiratory flow limitation }\end{array} \quad \begin{aligned} & \text { Unload respiratory muscles } \\ & \text { without further hyperinflation }\end{aligned}$

PEEPi with dynamic

hyperinflation due to absolute

(i.e. narrow endotracheal tube) or

relative (i.e. high minute ventilation)

increase in expiratory impedance

PEEPi without dynamic

hyperinflation due to expiratory

Applied PEEP $<$ PEEPi

Unload respiratory muscles with further hyperinflation 


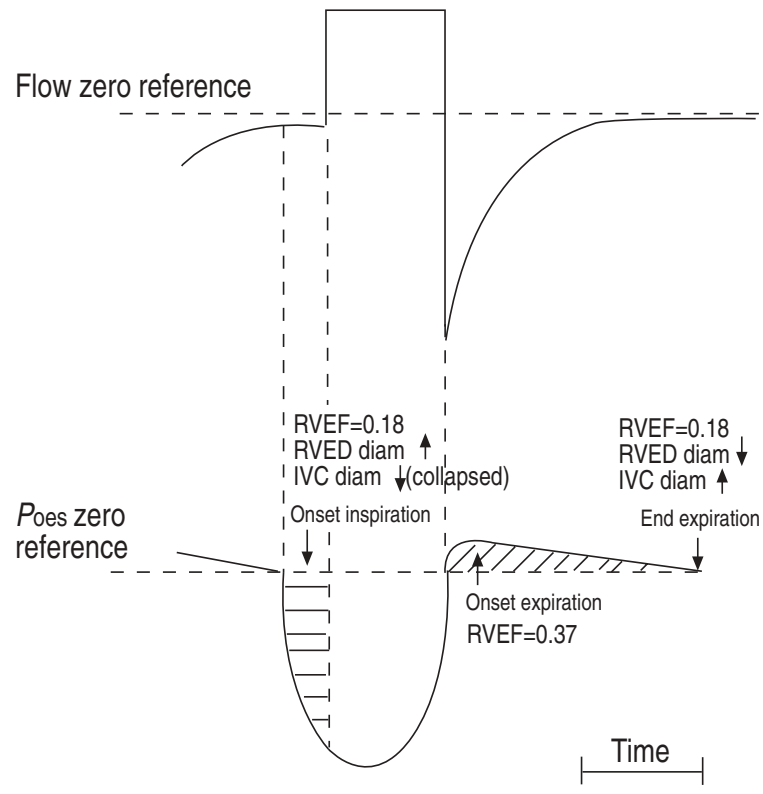

Fig. 1. - Phasic changes in right ventricular function during spontaneous ventilation in COPD patients. Horizontal hatching: inspiratory effort produced to overcome PEEPi; oblique hatching: expiratory recruitment of the abdominal muscle. (Reconstructed with data obtained from [28] and [29]). Poes: oesophageal pressure; COPD: chronic obstructive pulmonary disease; PEEPi: intrinsic positive end-expiratory pressure; RVEF: right ventricular ejection fraction; RVED: right ventricular end-diastolic; IVC: inferior vena cava.

to $24.5 \pm 13 \mathrm{mmHg}(\mathrm{p}<0.05)$. The same was true for the transmural values of right atrial pressure $(P$ ra $)$ and $\bar{P}$ pa. Cardiac index (CI) and stroke volume (SV) significantly increased as well as RVEDV, whilst RVEF did not change with spontaneous ventilation [17]. Recently, RICHARD et al. [23], studying 12 consecutive COPD patients without documented coronary artery disease, found that, during weaning, the shift from mechanical ventilation (pressure support) to spontaneous ventilation (T-piece) caused a progressive decrease in LVEF, which was directly related to an increase in left ventricular afterload due to the decrease in intrathoracic pressure consequent to the restoring of spontaneous ventilation.
Based on the data discussed previously, the haemodynamic profile of COPD patients during AVF and weaning seems to be characterized by RV dilation, due to changes in RV preload and afterload associated with concomitant alterations in LV function. The role of PEEPi might, therefore, be critical, since it can profoundly affect the cardiorespiratory interaction through its potential effects on dynamic hyperinflation, negative inspiratory swings of intrathoracic pressure, positive swings of abdominal pressure, and gas exchange (table 2).

\section{Dynamic hyperinflation}

Increases in lung volume above functional residual capacity may affect right ventricular afterload. In fact, PVR increases as much as lung volume increases [32]. An increase in right ventricular afterload with consequent reduction in cardiac output and rise in PAOP has been described in COPD patients during AVF [2]. This increase can be related to the increase in lung volume [33] and intrathoracic pressure [34] associated with PEEPi [2]. When lung volume is constant, any change in pleural pressure is accompanied by an approximately equal change in alveolar pressure. Conversely, when lung volume changes, alveolar pressure has to change relative to pleural pressure. The difference between alveolar and pleural pressure is the static elastic recoil pressure of the lungs, and lung volume cannot be changed without an accompanying change in the static recoil pressure of the lung [35]. Changes in lung volume may alter PVR. Since a considerable portion of the pulmonary blood vessels (alveolar vessels) is essentially exposed to alveolar pressure, a change in lung volume, such as in dynamic hyperinflated COPD patients, will affect pulmonary pressure through the effect of alveolar extravascular pressure on the pulmonary alveolar vessels. When alveolar pressure is greater than left atrial pressure (West's zone II condition), the alveolar vessels function as a Starling resistor. In this condition, the back pressure to flow is represented by the alveolar pressure rather than left atrial pressure.

Table 2. - Theoretical effects of PEEPi on cardiopulmonary interaction during weaning of COPD patients

$\begin{aligned} & \text { Dynamic } \\ & \text { hyperinflation }\end{aligned}$
$\begin{aligned} & \text { Large negative } \\ & \text { intrathoracic } \\ & \text { pressure with } \\ & \text { no changes } \\ & \text { in lung volume }\end{aligned}$

PEEPi: intrinsic positive-end expiratory pressure; COPD: chronic obstructive pulmonary disease; RV: right ventricle; $P$ ra: right atrial pressure; $P$ ab: abdominal pressure. 
The higher back pressure requires an increase in pulmonary arterial pressure approximately equal to alveolar pressure in order to maintain pulmonary blood flow, and the right ventricle must produce a greater myocardial effort to maintain flow. Thus, the increase in alveolar pressure relative to pleural pressure produces an increase in alveolar right ventricular afterload due to the rise in back pressure. In this respect, in COPD patients PEEPi may contribute to an increase in right ventricular afterload by increasing alveolar pressure.

\section{Inspiratory threshold load}

The presence of PEEPi requires that inspiratory muscles must generate sufficient force to overcome the opposite recoil pressure before inspiratory flow can begin. In this respect, PEEPi acts as an inspiratory threshold load and represents an additional impedance, which the muscles must face. The respiratory muscle of COPD patients must, hence, generate more negative swings in pleural pressure in order to initiate the breath during spontaneous and/or assisted ventilation [9, 10]. Furthermore, KAWAGOE et al. [28], in a canine model of expiratory flow limitation, showed that the increase in inspiratory muscle effort due to hyperinflation and PEEPi did not occur jointly with an increase in diaphragmatic blood flow. On the contrary, when hyperinflation and PEEPi were induced by resistive loading (i.e. with no expiratory flow limitation) the same increase in work of breathing was followed by an increase in diaphragmatic blood flow. The authors concluded that changes in systemic haemodynamics or local stresses on the respiratory muscles related to PEEPi due to expiratory flow limitation may impede the perfusion of the diaphragm, and this may contribute to respiratory muscle failure in COPD [28].

Different haemodynamic profiles can be expected as a direct consequence of dynamic hyperinflation and PEEPi. On the one hand, an increase in lung volume may impede venous return, both directly through compression of the vena cava [29] and right heart [36], and indirectly through an increase in $P$ ra, which can reduce the pressure gradient for venous return [37]. On the other hand, $P$ ra will decrease consequent to the transmission of the large negative inspiratory swings transmitted to the intrathoracic vascular structures. This is expected to enhance the pressure gradient for venous return. When Pra decreases below atmospheric pressure, the increase in venous return is limited by the occurrence of collapse of the large veins as they enter the thorax [38]. However, when collapse of the large veins occurs, the venous return is in the flat part of the venous return curve, i.e. maximal venous return has been reached [38]. Therefore, the abnormal increase in pleural negativity during the inspiration due to PEEPi may increase venous return, explaining the increase in right ventricular preload described in COPD patients during spontaneous inspiration [39].

Since the early phase of inspiration (when PEEPi is not overcome) is not associated with increase in lung volume, the fostering effect on venous return is not counterbalanced by potential mechanical compression on IVC or increase in $P$ ra caused by lung volume increase. The early phase of inspiration in the presence of PEEPi should be, to some extent, equivalent to a Müller manoeuvre (decrease in pleural pressure with no change in lung volume) [40] or to acute asthma [41, 42]. Under these conditions, the following sequence of phenomena should occur: increase in venous return; increase in RV septumfree wall dimension and leftward displacement of the septum; and decrease in LV dimension and filling [43, 44]. These effects should decrease SV through the leftward shift of the interventricular septum (ventricular interdependence). The PEEPi-induced increase in pleural negativity during inspiration is also an aggravating factor for right ventricular afterload. During inspiration prior to PEEPi being overcome, pressure around the right ventricle decreases, whilst alveolar pressure does not change so the right ventricle must generate higher pressures, i.e. right ventricular afterload increases, in order to counterbalance negative transmural pressure.

\section{Abdominal pressure}

LEMAIRE et al. [17] observed that transmural left ventricular filling pressure markedly increased when weaning from mechanical ventilation was attempted in COPD patients. Commenting on the study by Lemaire et al. [17], Permutt [45] pointed out that the translocation of blood from the peripheral to the central circulation was the major contributory factor to unsuccessful weaning [45]. The development of significant transdiaphragmatic pressure during the weaning trial was invoked to explain such findings [45]. During spontaneous ventilation, the descent of the diaphragm produces a fall in pleural pressure and an increase in abdominal pressure, resulting in an increase in transdiaphragmatic pressure. From the haemodynamic point of view, abdominal pressure increases whilst right atrial pressure decreases. This would enhance venous return. The splanchnic circulation acts as a functional reservoir to adjust venous return and preload during various types of physiological stress, such as exercise, and changes in posture or in environmental temperature. The mechanical properties of splanchnic blood vessels make them especially sensitive to changes in the pressure on their outer surface [46]. On the basis of these considerations, it is likely that the cause of the increase in preload during weaning, in the study by LEMAIRE et al. [17], was the increase in transdiaphragmatic pressure rather than the fall in oesophageal pressure [45]. If the abdominal viscera are congested and the compliance of the abdominal cavity reduced, the transdiaphragmatic pressure will increase more to provide the same tidal volume during spontaneous ventilation, enhancing the effects of transdiaphragmatic pressure on the gradient for the venous return [45]. This enhancement of venous return occurs, in particular, in the presence of normo- and hypervolaemia, whilst in hypovolaemia the effects of transdiaphragmatic pressure on venous return may be reversed. In fact, in the study by LEMAIRE et al. [17], the patients who failed the first weaning trial underwent diuretic therapy. The successive weaning trial proved to be successful.

The relationship between right atrial pressure and abdominal pressure determining venous return has been elegantly described by TAKATA and co-workers [47, 48], who used the concept of a vascular waterfall in the abdominal vena cava at the thoracic inlet to account for 
respiratory induced changes in venous return. The essential feature of the model of TAKATA and co-workers [47, $48]$ is that the abdominal venous compartment can be have either as a capacitor or as a Starling resistor, depending on the reciprocal relationship between abdominal and right atrial pressures. An increase in abdominal pressure would enhance inferior vena cava return (two-thirds of total venous return) when $P$ ra exceeds abdominal pressure (capacitance effect or abdominal zone III, similar to West's pulmonary zone III), but would reduce IVC return when right atrial pressure is below abdominal pressure, due to the development of a vascular waterfall (Starling resistor effect or abdominal zone II, similar to West's pulmonary zone II).

In COPD patients, different patterns of breathing have been reported, which can have a different effect on venous return. DeCRAMER et al. [49] note that pressure swings in the abdomen are greater where the force is applied than in sites more distant from the site of application. In COPD patients, during quiet breathing and unsuccessful weaning trials, recruitment of abdominal muscle may occur. Therefore, the abdominal muscle would generate a greater pressure on the external part of the splanchnic vasculature than on the inferior vena cava at the thoracic inlet. Under these circumstances, the abdominal vascular compartment should behave as an abdominal zone II, and abdominal breathing might enhance venous return. On the other hand, in the diaphragmatic pattern of breathing, the diaphragmatic descent would operate a mechanical compression on the liver. This compression is independent from any effect on the generalized abdominal pressure produced by diaphragmatic descent, since it also occurs with an open abdomen [50]. The compression on the liver surface from the downward displacement of the diaphragm could reduce the diameter and/or the number of the perfused sinusoidal channels, and cause an increase in splanchnic venous resistance, and a decrease in splanchnic venous return [51], simulating an abdominal zone III. However, Murciano et al. [52] showed that in most COPD patients, there is little change in gastric pressure during spontaneous respiration. Even though, during diaphragmatic descent, gastric pressure may not be a good indicator of the pressure exerted under the crural or the costal diaphragm [49], in COPD patients the diaphragm is reported to act as a fixator [53]. Therefore, in COPD patients where the diaphragmatic descent is altered, mechanical compression of the splanchnic vasculature and the reduction in splanchnic venous return would be less likely to occur.

\section{Gas exchange}

Using the multiple inert gas elimination technique, TORRES et al. [54] and BEYDON et al. [55] studied the ventilation-perfusion $\left(V^{\prime} \mathrm{A} / Q^{\prime}\right)$ relationship in COPD patients during mechanical ventilation and again during weaning (spontaneous ventilation). Both studies showed that the major determinant of the worsening in $V^{\prime} \mathrm{A} / Q^{\prime}$ distribution during weaning was a critical alteration of the ventilatory pattern due to an increase in respiratory rate and a decrease in tidal volume. Indices of $V^{\prime} \mathrm{A} / Q^{\prime}$ inequality worsened during weaning, indicating that a significant redistribution of pulmonary blood flow to low
$V^{\prime} \mathrm{A} / Q^{\prime}$ areas occurred when patients were breathing spontaneously. Consequently, alveolar ventilation fell, arterial carbon dioxide tension $\left(\mathrm{Pa}, \mathrm{CO}_{2}\right)$ increased, and $\mathrm{pH}$ diminished. Hypercapnia and respiratory acidosis increase venous return [56], whilst hypoxaemia and respiratory acidosis enhance pulmonary hypertension [57]. A direct relationship between hypercapnia, respiratory acidosis and PEEPi has never been demonstrated experimentally. However, in a recent study, Rossi and co-workers [58] studied the effects of PEEPi reduction on $V^{\prime} \mathrm{A} / Q^{\prime}$ mismatching in eight COPD patients during controlled mechanical ventilation. After reduction of PEEPi to $50 \%$ of the initial value, obtained by increasing expiratory time and decreasing respiratory rate and tidal volume, Rossi and co-workers [58] observed a deterioration of $V^{\prime} \mathrm{A} / Q^{\prime}$ distribution, which was due mostly to a reduction in minute ventilation together with an increase in cardiac index. Because arterial oxygen tension $\left(\mathrm{Pa}_{\mathrm{a}} \mathrm{O}_{2}\right)$ was kept in the upper part of the haemoglobin dissociation curve, arterial oxygen content remained unchanged. Thus, the increase in cardiac index, without variations in oxygen consumption, determined a significant rise in systemic oxygen supply to the tissue.

\section{Effects of CPAP on cardiopulmonary interaction during weaning of COPD patients}

Several studies $[9,10]$ have shown that low levels of CPAP can reduce the inspiratory swings in oesophageal and transdiaphragmatic pressure, as well as the amount of paradoxical motion and of expiratory recruitment of the abdominal muscle $[59,60]$. This was accounted for by a reduction in PEEPi and in the elastic work performed; the resistive work of breathing being unchanged. Hence, interpretation of the impact of CPAP on the cardiopulmonary interaction during the weaning period of COPD patients must take into consideration its effects on dynamic hyperinflation, negative inspiratory deflection of intrathoracic pressure, positive swing of abdominal pressure, and gas exchange (table 3 ).

\section{Dynamic hyperinflation}

In patients with acute lung injury, an increase in right ventricular afterload determining a reduction in cardiac index has been described only at PEEP levels higher than $15 \mathrm{cmH}_{2} \mathrm{O}$ [8]. This effect on right ventricular afterload was caused by an increase in lung volume and in alveolar pressure, relative to pericardial pressure [61]. When PEEPi due to expiratory flow limitation is present, application of CPAP levels lower than $P$ crit are not expected to increase lung volume and alveolar pressure. Therefore, CPAP levels lower than $P$ crit should not cause any further increase in right ventricular impedance.

\section{Inspiratory threshold load}

Since an external CPAP is able to counterbalance $\mathrm{PEEPi}$, tidal ventilation will require less inspiratory effort. As a consequence, the respiratory muscles will have to develop less negative pleural pressure swings to initiate inspiration. Therefore, less reduction in intrathoracic pressure will occur and venous return to the right ventricle 
Table 3. - Theoretical effects of continuous positive airway pressure (CPAP) counterbalancing PEEPi on cardiopulmonary interaction during weaning of COPD patients

CPAP

\begin{tabular}{|c|c|c|c|}
\hline $\begin{array}{l}\text { Dynamic } \\
\text { hyperinflation }\end{array}$ & $\begin{array}{l}\text { No further increase } \\
\text { in lung volume }\end{array}$ & $=$ & RV impedance \\
\hline $\begin{array}{l}\text { Large negative } \\
\text { intrathoracic } \\
\text { pressure with } \\
\text { no changes } \\
\text { in lung volume }\end{array}$ & $\begin{array}{l}\text { Reduction in inspiratory } \\
\text { intrathoracic pressure }\end{array}$ & 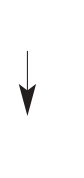 & $\begin{array}{l}\text { Venous return to RV and } \\
\text { reversal of leftward shift } \\
\text { of the septum }\end{array}$ \\
\hline $\begin{array}{l}\text { Large positive } \\
\text { abdominal pressure }\end{array}$ & $\begin{array}{l}\text { Reduction of paradoxical motion } \\
\text { and expiratory recruitment } \\
\text { of abdominal muscules }\end{array}$ & $\uparrow \downarrow$ & $\begin{array}{l}\text { Venous return and collapse } \\
\text { of vena cava according to } \\
\text { the } P_{\text {ra }}-P_{\mathrm{ab}} \text { relationship }\end{array}$ \\
\hline $\begin{array}{l}\text { Worsening of } \\
\text { hypercapnia/hypoxia }\end{array}$ & Improvement of $V^{\prime} \mathrm{A} / Q^{\prime}$ & $\downarrow$ & $\begin{array}{l}\text { RV impedance and } \\
\text { venous return to RV }\end{array}$ \\
\hline
\end{tabular}

$V^{\prime} \mathrm{A} / Q^{\prime}$ : alveolar perfusion/ventilation ratio. For further abbreviations see legend to table 2 .

is expected to decrease. In figure 2, IVC flow velocity during spontaneous breathing (SB) and CPAP of $5 \mathrm{cmH}_{2} \mathrm{O}$ is shown in a representative COPD patient $(\mathrm{PEEPi}=8$ $\mathrm{cmH}_{2} \mathrm{O}$ ) during weaning from mechanical ventilation. On average, IVC flow velocity was approximately double during SB than during CPAP. Interestingly, the relationship between respiratory phases and the diameter of the IVC differed between SB and CPAP. During inspiration (fig. 3c and d), IVC collapsed at the diaphragmatic level during SB (fig. 3c), whilst remaining open during CPAP (fig. 3d). During expiration (fig. 3a and b) IVC remained open during both SB (fig. 3a) and CPAP (fig. $3 b)$. The evaluation of left ventricular filling by examination of mitral flow (fig. 4) shows that application of CPAP also reduced mitral flow. The increase in pleural pressure negativity due to PEEPi seemed to have a great effect on IVC flow. Application of low levels of CPAP was able to reduce the magnitude of intrathoracic inspiratory pressure swings, decreasing both venous return and its phasic alterations.

If venous return is reduced, the right ventricle will not dilate and the leftward shift of the interventricular septum will not occur $[43,44]$. In figure 5, four-chamber views of the heart obtained by transthoracic echocardiography and oesophageal pressure traces are shown. These images were obtained in a decompensated COPD patient during the weaning process. During relaxation of respiratory muscles and controlled mechanical ventilation (CMV) (fig. 5a), PEEPi amounted to $20 \mathrm{cmH}_{2} \mathrm{O}$ and the interventricular septum showed the normal rightward

a)

b)
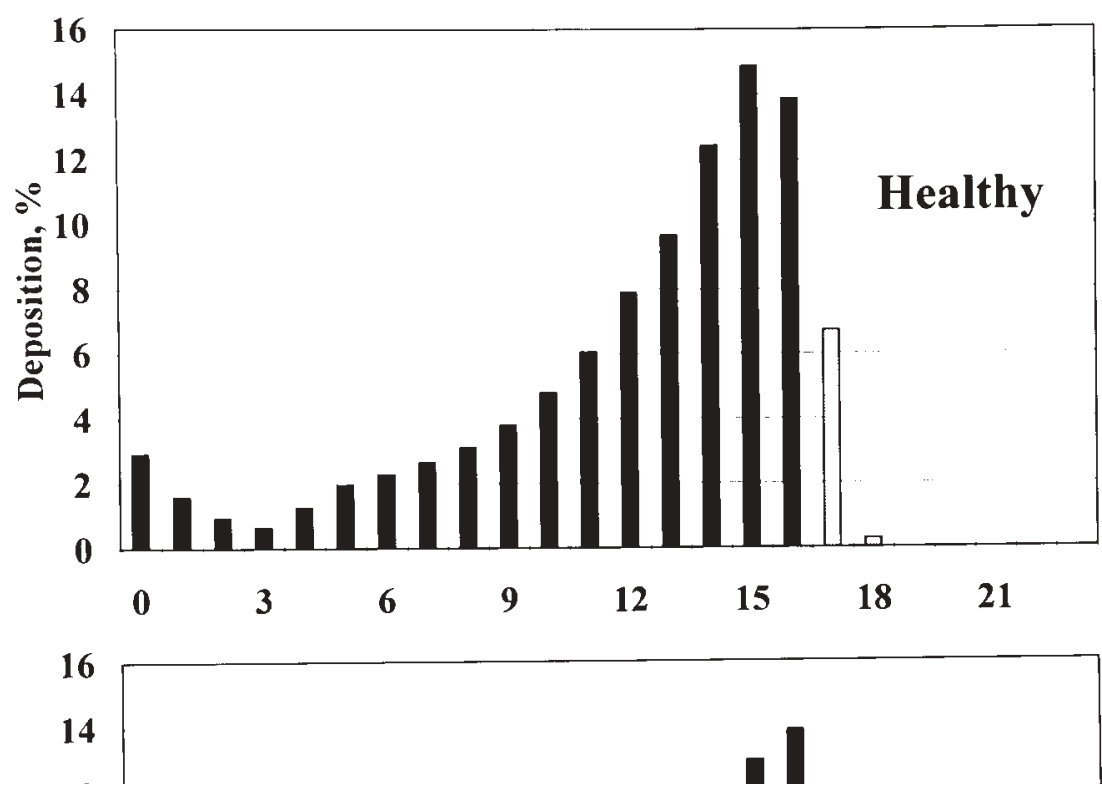

Fig. 2. - Effects of: a) spontaneous breathing (SB); and b) $5 \mathrm{cmH}_{2} \mathrm{O}$ of continuous positive airway pressure (CPAP) on inferior vena cava (IVC) flow velocity (Doppler echocardiography). Oesophageal pressure traces $(P$ oes $)$ obtained by an oesophageal balloon connected to a pressure transducer are also shown. Oesophageal pressure swings and IVC flow velocity are reduced by CPAP. 
a)

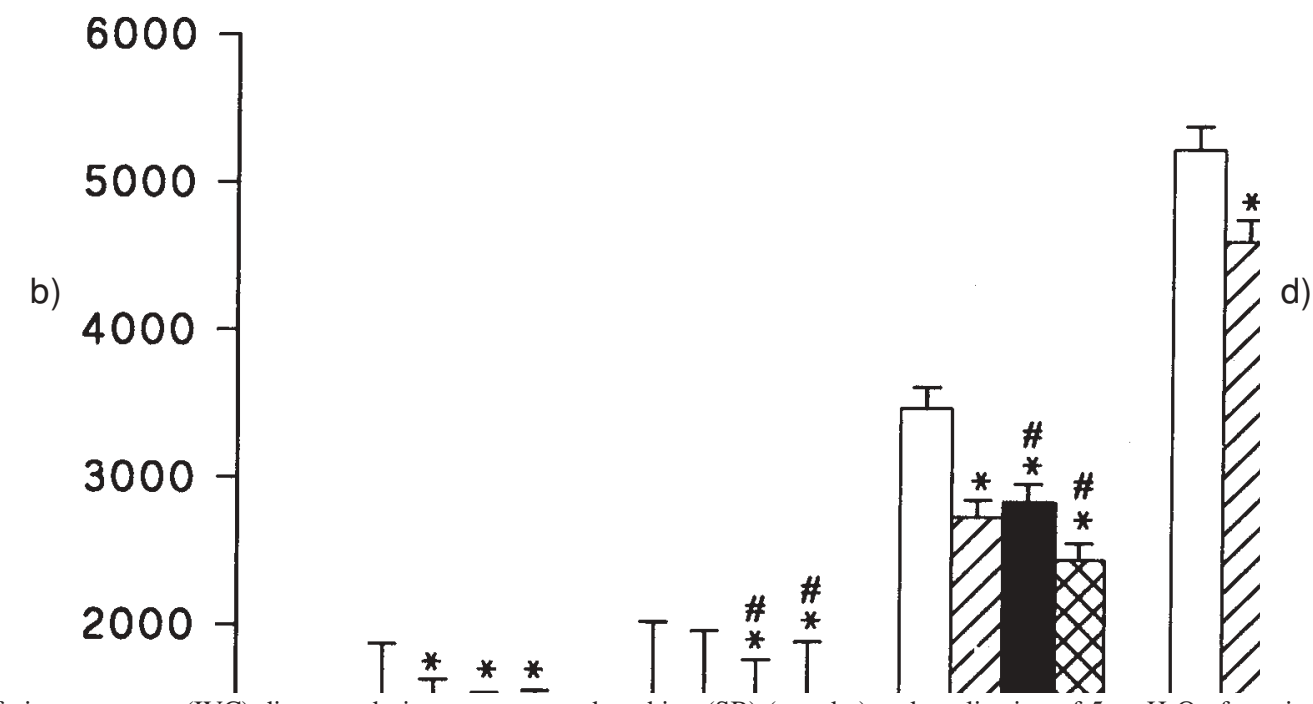

Fig. 3. - Inferior vena cava (IVC) diameter during spontaneous breathing (SB) (a and c) and application of $5 \mathrm{cmH}_{2} \mathrm{O}$ of continuous positive airway pressure (CPAP) (b and d). Expiratory (EXP) (a and b) and inspiratory (INSP) (c and d) phenomena are shown. IVA diameter is reduced during inspiration in SB. CPAP application blunted this phasic change in IVC diameter.

a)

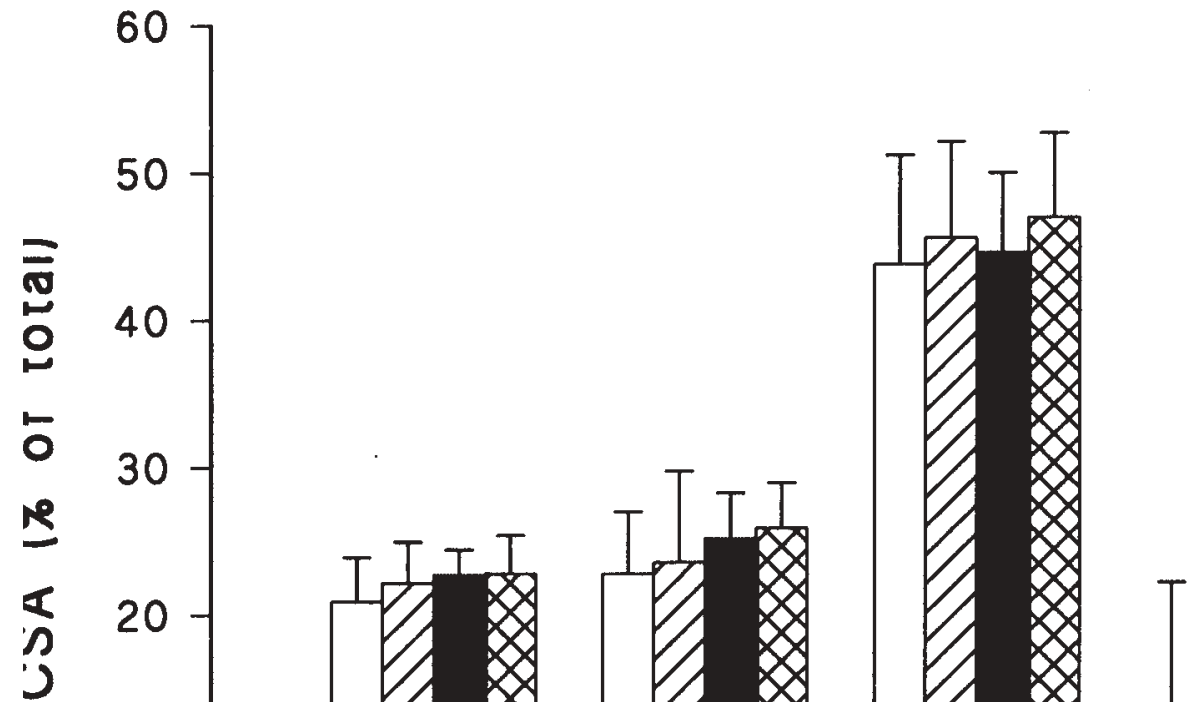

Fig. 4. - Mitral flow during: a) spontaneous breathing (SB); and b) $5 \mathrm{cmH}_{2} \mathrm{O}$ of continuous positive airway pressure (CPAP) on mitral flow (Doppler transthoracic echocardiography). Oesophageal pressure $(P$ oes $)$ traces are also shown. Following the application of CPAP mitral flow dropped from $100 \mathrm{~cm} \cdot \mathrm{s}^{-1}$ during $\mathrm{SB}$ to $80 \mathrm{~cm} \cdot \mathrm{s}^{-1}$ during $\mathrm{SB}$.

convexity. During spontaneous ventilation through a Ttube trial (fig. 5b), large inspiratory swings in oesophageal pressure were observed $\left(\Delta P_{\mathrm{oes}} \sim-15 \mathrm{cmH}_{2} \mathrm{O}\right)$ and the interventricular septum showed a clear leftward displacement. When a CPAP of $13 \mathrm{cmH}_{2} \mathrm{O}$ was applied (fig. $5 \mathrm{c})$, the negative swings of the oesophageal pressure were greatly reduced $\left(\Delta P\right.$ oes $\left.\sim-3 \mathrm{cmH}_{2} \mathrm{O}\right)$. Furthermore, application of CPAP reversed the leftward displacement observed during spontaneous breathing. Under these circumstances, in COPD patients, CPAP acts as a "mechanical" phlebotomy and, consistent with ancient indications [62], may unload the right ventricle. In fact, CPAP decreased left ventricular filling by one-third, as evaluated by mitral flow (fig. 6).

\section{Abdominal pressure}

Since several studies $[9,10]$ have reported that low levels of CPAP can reduce the amount of paradoxical motion and expiratory recruitment of the abdominal muscle [59, $60]$, a reduction in the potential effect of abdominal pressure on venous return would be expected. 
a)

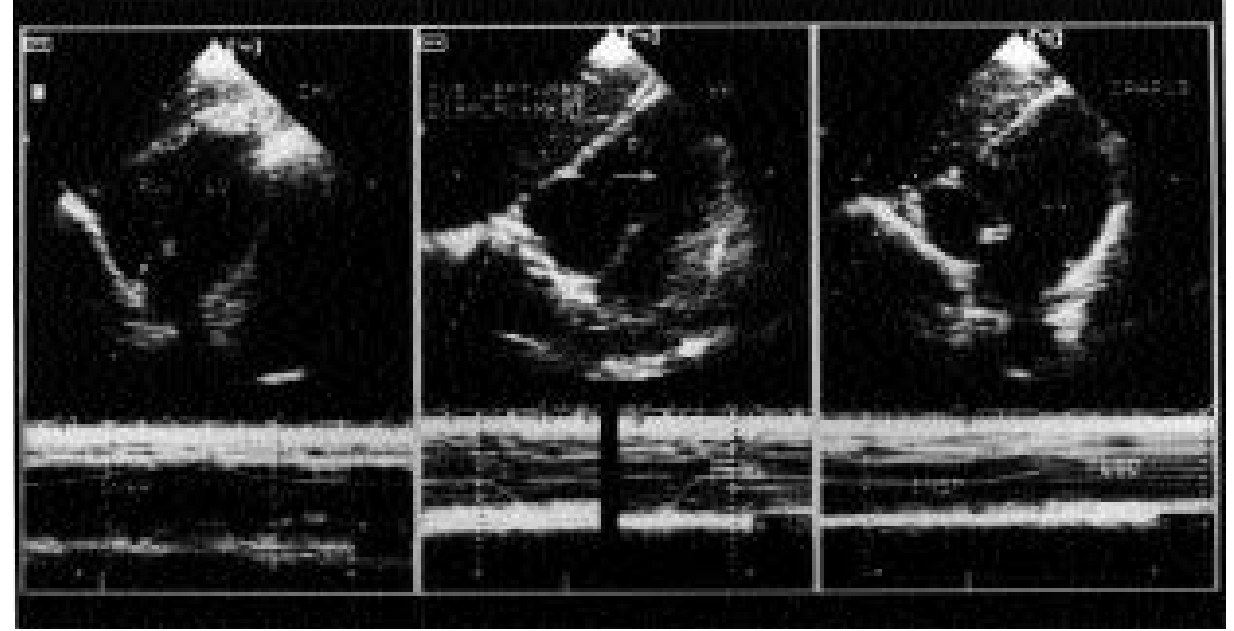

Fig. 5. - Four-chamber view of the heart (transthoracic echocardiography) in a chronic obstructive pulmonary disease (COPD) patient (PEEPi=20 $\mathrm{cmH}_{2} \mathrm{O}$ ) is shown during: a) controlled mechanical ventilation (CMV); b) spontaneous breathing (SB); and c) application of $13 \mathrm{cmH}_{2} \mathrm{O}$ of continuous positive airway pressure (CPAP). The arrow shows the leftward displacement of the interventricular septum (IVS) during SB. Application of CPAP reversed the displacement of the interventricular septum. PEEPi: intrinsic positive end-expiratory pressure.

a)

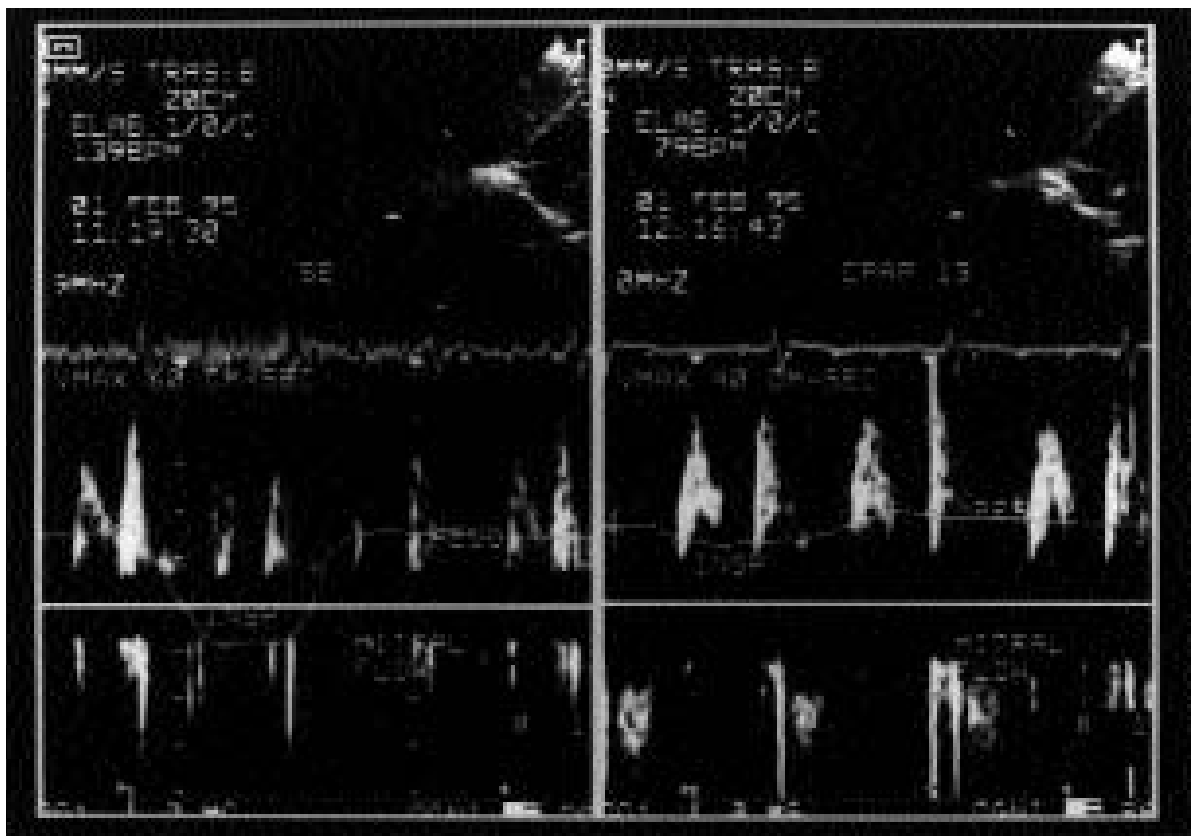

Fig. 6. - Mitral flow during: a) spontaneous breathing (SB); and b) application of $13 \mathrm{cmH}_{2} \mathrm{O}$ of continuous positive airway pressure. Application of CPAP decreased mitral flow from 60 to $40 \mathrm{~cm} \cdot \mathrm{s}^{-1}$ (note that the flow velocity scale is different on the two sides of the figure).

\section{Gas exchange}

Recently, Rossi and co-workers [58] showed that application of PEEP amounting to $50 \%$ of the original PEEP did not change respiratory mechanics or haemodynamics, but that $\mathrm{Pa}, \mathrm{O}_{2}$ increased and $\mathrm{Pa}, \mathrm{CO}_{2}$ fell. These beneficial effects of PEEP on arterial blood gas values are fully explained by changes in the $V^{\prime} \mathrm{A} / Q^{\prime}$ distribution, the lung being more efficient in terms of $\mathrm{O}_{2}$ uptake and $\mathrm{CO}_{2}$ clearance. In the absence of changes in cardiac output, minute ventilation and ventilatory pattern, the observed rightward shift of the $V^{\prime} \mathrm{A} / Q^{\prime}$ distribution has to be interpreted as a redistribution of blood flow and/or ventilation to lung units, that are more efficient in terms of gas exchange with PEEP counterbalancing PEEPi. Indeed, in COPD patients with dynamic hyperinflation and PEEPi due to expiratory flow limitation, lung inflation does not start from $V$ r. Because of the regional difference in rate of lung emptying, due to time constant inequalities [63], at the onset of lung inflation the short-time constant units can start filling whereas the long-time constant units are still emptying. Application of PEEP/CPAP, by decreasing PEEPi, will reduce the magnitude of such regional differences in alveolar pressure, leading to a more homogenous distribution of the inspired gas, and, hence, improving the efficiency of pulmonary gas exchange itself. 
In conclusion, mechanical ventilation and aggressive treatment of AVF in COPD patients have been shown to be relatively successful, despite the high cost of treatment [64]. Data presented in the literature appear to suggest that further outcome improvement and reduction in cost are to be expected when physiologically oriented therapeutic procedures are used. There is clear evidence supporting the use of PEEP/CPAP in COPD patients during the weaning phase in order to unload the respiratory muscle from the PEEPi due to expiratory flow limitation. If PEEPi is not due to flow limitation, application of CPAP/PEEP will cause further hyperinflation, worsening respiratory mechanics, muscle activity and haemodynamics. The physiological revisitation of the cardiopulmonary interaction in COPD patients during weaning from mechanical ventilation seems to suggest a specific role of PEEPi in causing impairment of cardiac function and eventually failure of the weaning attempt.

Application of positive end-expiratory pressure/continuous positive airway pressure in chronic obstructive pulmonary disease patients during weaning from mechanical ventilation may, unload respiratory muscles as well as the heart. Large prospective and, hopefully, randomized clinical studies are needed to show whether the physiological benefits consequent to the use of positive end-expiratory pressure and continuous positive airway pressure in chronic obstructive pulmonary disease patients with respiratory failure may improve the overall clinical management of these patients.

Acknowledgements: The authors thank J.L. Robotham, T. Fiore, A. Brienza and R. Giuliani for their suggestions and criticisms during the preparation of this review and for the support they have provided in the development of this research. They also thank N. Di Venere, Department of Cardiology, University of Bari, for his help in analysing the echocardiographic images.

\section{References}

1. Kimball WR, Leith DE, Robins AG. Dynamic hyperinflation and ventilatory dependence in chronic obstructive pulmonary disease. Am Rev Respir Dis 1982; 126: 991-995.

2. Pepe PE, Marini JJ. Occult positive end-expiratory pressure in mechanically ventilated patients with airflow obstruction: the auto-PEEP effect. Am Rev Respir Dis 1982; 126: 166-170.

3. Rossi A, Gottfried SB, Higgs BD, et al. Measurement of static compliance of the total respiratory system in patients with acute respiratory failure during mechanical ventilation. Am Rev Respir Dis 1985; 131: 672-677.

4. Gay CG, Rodarte JR, Hubmayer RD. The effects of positive expiratory pressures on isovolume flow and dynamic hyperinflation in patients receiving mechanical ventilation. Am Rev Respir Dis 1989; 139: 621-626.

5. Gottfried SB, Rossi A, Higgs BD, et al. Noninvasive determination of respiratory mechanics during mechanical ventilation for acute respiratory failure. Am Rev Respir Dis 1985; 131: 414-420.

6. Fleury B, Murciano D, Talamo C, Aubier M, Pariente $\mathrm{R}$, Milic-Emili J. Work of breathing in patients with obstructive pulmonary disease in acute respiratory failure. Am Rev Respir Dis 1985; 131: 822-827.

7. Broseghini C, Brandolese R, Poggi R, et al. Respiratory mechanics during the first day of mechanical ventilation in patients with pulmonary edema and chronic airway obstruction. Am Rev Respir Dis 1988; 138: 355-361.

8. Ranieri VM, Giuliani R, Cinnella G, et al. Physiologic effects of positive end-expiratory pressure in COPD patients during acute ventilatory failure and controlled mechanical ventilation. Am Rev Respir Dis 1993; 147: 5-13.

9. Smith TC, Marini JJ. Impact of PEEP on lung mechanics and work of breathing in severe airflow obstruction. J Appl Physiol 1988; 65: 1488-1499.

10. Petrof BJ, Legaré M, Goldberg P, Milic-Emili J, Gottfried SB. Continuous positive airway pressure reduces work of breathing and dyspnea during weaning from mechanical ventilation in severe chronic obstructive pulmonary disease. Am Rev Respir Dis 1990; 141: 281-289.

11. Gottfried SB. The role of PEEP in the mechanicallyventilated COPD patient. In: Marini JJ, Roussos C, eds. Ventilatory Failure. Berlin, Heidelberg, New York, Springer-Verlag, 1991; pp. 392-418.

12. Rossi A, Polese G, Brandi G, Conti G. Intrinsic positive end-expiratory pressure ( $\mathrm{PEEP} \mathrm{i})$. Intensive Care Med 1995; 21: 522-536.

13. Biernacki W, Flenley DC, Muir AL, MacNee W. Pulmonary hypertension and right ventricular function in patients with COPD. Chest 1988; 94: 1169-1175.

14. Macnee W. Pathophysiology of cor pulmonale in chronic obstructive pulmonary disease. Am J Respir Crit Care Med 1994; 150: 833-852.

15. Matthay RA, Berger HJ, Davies RA, Loke RA, Mahler DA, Gottschalk A. Right and left ventricular performance in chronic obstructive pulmonary disease: radionuclide assessment. Ann Intern Med 1983; 88: 234-239.

16. Mahler DA, Brent BN, Loke J, Zaret BL, Matthay RA. Right ventricular performance and central circulatory hemodynamics during upright exercise in patients with chronic obstructive pulmonary disease. Am Rev Respir Dis 1984; 130: 722-729.

17. Lemaire F, Tebul J-L, Cinotti L, et al. Acute left ventricular dysfunction during unsuccessful weaning from mechanical ventilation. Anesthesiology 1988; 69: 171179.

18. Tebull J-L, Abrouk F, Lemaire F. Right ventricular function in COPD patients during weaning from mechanical ventilation. Intensive Care Med 1988; 14: 483-485.

19. Fishman A. Chronic cor pulmonale. Am Rev Respir Dis 1976; 114: 775-794.

20. Dhainaut JF, Brunet F, Armaganidis A. Phasic changes of right ventricular ejection in acute exacerbation of COPD. Am Rev Respir Dis 1987; 135: A113.

21. Dhainaut JF, Brunet F. Phasic changes of right ventricular ejection fraction in patients with acute exacerbation of chronic obstructive pulmonary disease. Intensive Care Med 1987; 12: 214-215.

22. Marangoni S, Scalvini S, Schena M, Vitacca M, Quadri A, Levi G. Right ventricular diastolic function in chronic obstructive lung disease. Eur Respir J 1992; 5: 438-443.

23. Richard C, Tebul J-L, Archambaud F, Hebert J-L, Michaut P, Auzepy P. Left ventricular function during weaning of patients with chronic obstructive pulmonary disease. Intensive Care Med 1994; 20: 181-186.

24. Matthay RA, Niederman MS, Wiedemann HP. Cardiovascular pulmonary interaction in chronic obstructive pulmonary disease with special reference to the pathogenesis and management of cor pulmonale. Med Clin North Am 1990; 74: 571-617.

25. Weber K, Janicki J, Shroff SG, Likoff MJ, St John Sutton 
MG. The right ventricle: physiology and pathophysiologic consideration. Crit Care Med 1983; 11: 323-328.

26. Macnee W. Pathophysiology of cor pulmonale in chronic obstructive pulmonary disease. Am J Respir Crit Care Med 1994, 150: 833-852.

27. Matthay RA, Arroliga AC, Wiederman HP, Schulman DS, Mahler DA. Right ventricular function at rest and during exercise in chronic obstructive pulmonary disease. Chest 1992; 101: 255S-262S.

28. Kawagoe Y, Permutt S, Fessler HE. Hyperinflation with intrinsic PEEP and respiratory muscle blood flow. $J$ Appl Physiol 1994; 77: 2440-2448.

29. Nakhjavan FK, Palmer WH, McGregor M. Influence of respiration on venous return in pulmonary emphysema. Circulation 1966; 33: 8-16.

30. Settle HP, Engel PJ, Fowler NO. Echocardiographic study of the paradoxical arterial pulse in chronic obstructive lung disease. Circulation 1980; 62: 1297-1307.

31. Jardin F, Gueret P, Prost JF, Farcot JC, Ozier Y, Bourdarias JP. Two-dimensional echocardiographic assessment of left ventricular function in chronic obstructive pulmonary disease. Am Rev Respir Dis 1984; 129: 135-142.

32. Whittenberger JL, Mc Gregor M, Berglund E. Influence of state of inflation of the lung on pulmonary vascular resistance. J Appl Physiol 1960; 15: 878-882.

33. Robotham JL, Lixfeld W, Holland L MacGregor D, Bryan AC, Rabson J. Effects of respiration on cardiac performance. J Appl Physiol : Respirat Environ Exercise Physiol 1978; 44: 703-709.

34. Thomas W, Griffo ZJ, Roose A. Effect of negative-pressure inflation of the lung on pulmonary vascular resistance. J Appl Physiol 1961; 16: 451-456.

35. Robotham JL. Cardiovascular disturbances in chronic respiratory insufficiency. Am J Cardiol 1981; 47: 952-962.

36. Brookhart JM, Boyd TE. Local differences in intrathoracic pressure and their relation to cardiac filling pressure in the dog. Am J Physiol 1947; 148: 434-444.

37. Pinsky MR. Determinants of pulmonary artery flow variation during respiration. J Appl Physiol: Respirat Environ Exercise Physiol 1984; 56: 1237-1245.

38. Guyton AC, Lindsey AW, Abernathy B. Venous return at various right atrial pressures and the normal venous return curve. Am J Physiol 1957; 189: 609-615.

39. Sylvester JT, Goldberg HS, Permutt S. The role of the vasculature in the regulation of cardiac output. Cardiol Clin 1986; 4: 333-348.

40. Brinker J, Weiss J, Lappé D, et al. Leftward septal displacement during right ventricular loading in man. Circulation 1980; 61: 626-632.

41. Jardin F, Farcot JC, Boisante L, Prost J-F, Guèret P, Bourdarias JP. Mechanism of paradoxic pulse in bronchial asthma. Circulation 1982; 66: 887-894.

42. Jardin F, Guéret P, Dubourg O, Farcot JC, Margairez A, Bourdarias JP. Inspiratory impairment in right ventricular performance during acute asthma. Chest 1987; 92: 789-795.

43. Iliceto S, Dambrosio M, Sorino M, et al. Effects of acute intrathoracic pressure changes on left ventricular geometry and filling. Am Heart $J$ 1988; 116: 455-465.

44. Palacios I, Poweres E, Powell WJ Jr. Effect of end-diastolic volume on the canine left ventricular ejection fraction. Am Heart J 1985; J109: 1059-1061.

45. Permutt S. Circulatory effects of weaning from mechanical ventilation: the importance of transdiaphragmatic pressure. Anesthesiology 1988; 69: 157-160.

46. Permutt S, Wise RA. The control of cardiac output through coupling of heart and blood vessels. In: Yin FCP, ed. Ventricular/vascular coupling. New York, SpringerVerlag, 1986; pp. 159-179.

47. Takata M, Wise RA, Robotham JL. Effects of abdominal pressure on venous return: abdominal vascular zone conditions. J Appl Physiol 1990; 69: 1961-1972.

48. Takata M, Robotham JL. Effects of inspiratory diaphragmatic descent on inferior vena caval venous return. $J$ Appl Physiol 1992; 72: 597-607.

49. Decramer M, De Troyer A, Kelly S, Zocchi L, Macklem PT. Regional differences in abdominal pressure swings in dogs. J Appl Physiol:Respirat Environ Exercise Physiol 1984, 57: 1682-1687.

50. Moreno AH, Burchell AR, Van Der WR, Burke JH. Respiratory regulation of splanchnic and systemic venous return. Am J Physiol 1967; 213: 455-465.

51. Brienza N, Revelly JP, Ayuse T, Robotham JL. Effects of PEEP on liver arterial and venous blood flows. $A m$ J Respir Crit Care Med 1995; (in press).

52. Murciano D, Aubier M, Bussi S, Derenne JP, Pariente R, Milic Emili J. Comparison of esophageal, tracheal and mouth occlusion pressure in patients with chronic obstructive pulmonary disease during acute respiratory failure. Am Rev Respir Dis 1982; 126: 837-841.

53. Derenne JP, Fleury B, Pariente R. Acute respiratory failure of chronic obstructive pulmonary disease. Am Rev Respir Dis 1988; 138: 1006-1033.

54. Torres A, Reyes A, Roca J, Wagner PD, RodriguezRoisin R. Ventilation-perfusion mismatching in chronic obstructive pulmonary disease. Am Rev Respir Dis 1989; 140: 1246-1250.

55. Beydon L, Cinotti L, Rekik N, et al. Changes in distribution of ventilation and perfusion associated with separation from mechanical ventilation in patients with obstructive pulmonary disease. Anesthesiology 1991; 75: 730-738.

56. Walley KR, Lewis TH, Wodd LDH. Acute respiratory acidosis decreases left ventricular contractility but increases cardiac output in dogs. Circ Res 1990; 67: 628635.

57. Lloyd TC. Influence of blood $\mathrm{pH}$ on hypoxic pulmonary vasoconstriction. J Appl Physiol 1966; 21: 358-364.

58. Rossi A, Santos C, Roca J, Torres A, Félez MA, RodriguezRoisin R. Effects of PEEP on $V^{\prime} \mathrm{A} / Q^{\prime}$ mismatching in ventilated patients with chronic airflow obstruction. Am J Respir Crit Care Med 1994; 149: 1077-1084.

59. Petrof BJ, Calderini E, Gottfried SB. Effect of CPAP on respiratory effort and dyspnea during exercise in severe COPD. J Appl Physiol 1990; 69: 179-188.

60. Petrof BJ, Kimoff RJ, Levy RD, Cosio MG, Gottfried SB. Nasal continuous positive airway pressure facilitates respiratory muscle function during sleep in severe chronic obstructive pulmonary disease. Am Rev Respir Dis 1991; 143: 928-935.

61. Pinsky M, Desmet J-M, Vincent J-L. Effect of positive end-expiratory pressure on right ventricular function in humans. Am Rev Respir Dis 1991; 143: 25-31.

62. Coope R. In: Diseases of the chest. Edinburgh, Livingstone, 1945; p. 443.

63. Grimby G, Takishima T, Graham W, Macklelm PT, Mead J. Frequency dependence of flow resistance in patients with obstructive lung disease. J Clin Invest 1968; 47: 1455-1465.

64. Gritti R, Ragazzi R, Pavoni V, Paparella L, Alvisi R, Capuzzo M. La sopravvivenza in terapia intensiva di pazienti con broncopneumopatia cronica ostruttiva e insufficenza respiratoria acuta sottoposti a ventilazione meccanica. Minerva Anestesiol 1994; 60: 695-670. 